\title{
ANALISIS IMPLEMENTASI KEBIJAKAN TENTANG GERAKAN NAGARI PEDULI TUBERKOLOSIS DI KENAGARIAN MAGEK KECAMATAN KAMANG MAGEK KABUPATEN AGAM TAHUN 2018
}

Novfattra, Hardisman ${ }^{2}$, Rima Semiarty ${ }^{2}$

\begin{abstract}
Abstrak
Angka penemuan penderita Tuberkulosis (TB) di Kabupaten Agam dari tahun 2015 sampai tahun 2017 mengalami penurunan. Kebijakan tentang Gerakan Nagari Peduli Tuberkulosis diwujudkan sebagai suatu Kebijakan Pemerintah Kabupaten Agam untuk penanggulangan penyakit Tuberkulosis. Tujuan penelitian ini adalah menganalisis pencapaian dan kendala yang dihadapi dalam Imlmementasi tentang Gerakan Nagari Peduli Tuberkulosis di Kenagarian Magek Kecamatan Kamang Magek Kabupaten Agam. Penelitian ini menggunakan metode kualitatif melalui wawancara mendalam, observasi dan telaah dokumen. Pengumpulan data dilakukan dengan wawancara lima orang informan yaitu Kepala Dinas Kesehatan Kabupaten Agam, Kepala Bidang Pencegahan dan Penanggulangan Penyakit, Kepala Seksi Kepala Bidang Pencegahan dan Penanggulangan Penyakit, Kepala Puskesmas Magek, Pemegang Program Tuberkulosis Puskesmas Magek dan Wali Nagari Magek. Komponen yang diteliti mengenai Input (kebijakan, tenaga, dana, sarana prasarana, dan metode), proses (perencanaan, pelaksanaan, pengawasan), output (pencapaian program penemuan penderita Tuberkulosis). Hasil penelitian menunjukkan bahwa pelaksanaan kebijakan Gerakan Nagari Peduli TB belum berjalan dengan baik. Penyediaan sarana prasarana dan alokasi anggaran khusus yang belum memadai dari Dinas Kesehatan dan Puskesmas Magek menjadi penyebabnya. Kata kunci: tuberkulosis, gerakan nagari peduli TB, kelompok kader nagari peduli TB, penemuan penderita
\end{abstract}

\section{Abstract}

The number of Tuberculosis (TB) sufferers in Agam Regency from 2015 to 2017 has decreased. The policy on the Care Village for Tuberculosis Movement was manifested as a policy of the Agam Regency Government for the prevention of Tuberculosis. The objective of this study was to analyze the achievements and constraints faced in the implementation of the Movement for the Care of Tuberculosis Nagari in Kenagarian Magek, Kamang Magek District Agam Regency. This study used a qualitative method through in-depth interviews, observation and document review. Data collection was conducted by interviewing five people, namely Head of Agam District Health Office, Head of Disease Prevention and Management, Head of Section for Disease Prevention and Control, Head of Magek Health Center, Program Holder Magek Health Center Tuberculosis and head village Magek. The components studied regarding inputs (policies, personnel, funds, infrastructure, and methods), processes (planning, implementation, supervision), output (achievement of Tuberculosis sufferer discovery programs). The results of the study indicate that the implementation of the Tuberculosis Care Village Concern policy has not gone well. Provision of infrastructure facilities and inadequate special budget allocations from health center were the caused of that.

Keywords: tuberculosis, the TB care village movement, the TB care cadre group, patient discovery

Affiliasi penulis: 1. Dinas Kesehatan Kabupaten Agam 2. Bagian IImu Kesehatan Masyarakat Fakultas Kedokteran Uiversitas Andalas Padang (FK Unand).
Korespondensi : Novfattra, email: fatra1980@gmail.com Nomor Hp: 082384846269 


\section{PENDAHULUAN}

Pembangunan kesehatan merupakan salah satu dari upaya pembangunan nasional yang diselenggarakan secara berkesinambungan yang terarah dan terpadu. Pembangunan kesehatan memiliki tujuan untuk meningkatkan kesadaran, kemauan, dan kemampuan hidup sehat setiap masyarakat demi terwujudnya derajat kesehatan seluruh rakyat Indonesia. ${ }^{1}$ Salah satu sasaran pembangunan kesehatan adalah meningkatkan pengendalian penyakit sasaran tersebut dikembangkan menjadi sasaran yang lebih kecil yaitu pengendalian angka kesakitan penyakit menular Tuberkulosis. $^{2}$

Berdasarkan laporan Global Tuberculosis Report WHO pada tahun 2017 Indonesia menduduki rangking ke-2 setelah India. ${ }^{3}$ Diperkirakan ada 1.000.000 kasus TB baru pertahun (399 per 100.000 penduduk) dengan 100.000 kematian pertahun (41 per 100.000 penduduk). ${ }^{4}$ Data Profil Kesehatan Indonesia tahun 2016, tercatat peningkatan kasus TBC dari 330.729 kasus di tahun 2015 menjadi 351.893 kasus di tahun $2016 .^{5}$

Angka prevalensi TB Indonesia adalah 0.4\%, terdapat 400 orang terdiagnosis menderita TB Paru positif dari setiap 100.000 penduduk. Angka prevalensi TB tertinggi terdapat di Jawa Barat (0.7\%), Papua (0.6\%), DKI Jakarta (0.6\%), Gorontalo (0.5\%), Banten $\left(0.4 \%\right.$, Papua Barat $(0.4 \%)^{6}$. Angka prevalensi TB yang masih tinggi, Kemenkes membuat Rencana strategis tahun 2015-2019 yaitu menurunkan prevalensi TB dari 297 per 100.000 penduduk pada tahun 2013 menjadi 245 per 100.000 pada tahun $2019 .^{2}$

Upaya Penanggulangan TB adalah program nasional yang dilakukan secara serentak di seluruh Indonesia. Untuk menilai kemajuan atau keberhasilan Program Penanggulangan TB maka digunakan beberapa indikator. Indikator tersebut diantaranya adalah Case Notification Rate (CNR), angka penjaringan suspek dan proporsi TB BTA positif diantara suspect TB. Indikator CNR menunjukkan jumlah seluruh pasien TB yang ditemukan dan tercatat diantara 100.000 penduduk di suatu wilayah. ${ }^{4}$

Prevalensi TB di Sumatera Barat adalah 0.2\%. Angka kasus baru TB BTA positif sebesar 4.597 kasus dengan Case Notification Rate (CNR) 87.5 per 100.000 penduduk. ${ }^{6}$ Angka BTA+ yang diobati pada tahun 2016 adalah sebanyak 4.685 kasus dengan angka kesembuhan $81.8 \% .^{7}$ Cakupan penemuan terduga Tuberkulosis di Provinsi Sumatera Barat berasal dari semua Kabupaten/Kota termasuk dari Kabupaten Agam. Pencapaian penemuan penderita TB paru BTA+ di Kabupaten Agam tahun 2016 sebanyak 343 kasus (54.44\%) dari yang ditetapkan sebanyak 630 kasus dan pada tahun 2017 pencapaian sebanyak 363 kasus (46.83\%). ${ }^{8}$

Strategi Nasional dalam penanggulangan TB dalam upaya Indonesia Bebas TB antara lain penguatan kepemimpinan program dan dukungan sistem, peningkatan akses layanan Temukan TB Obati Sampai Sembuh (TOSS-TB), pengendalian faktor risiko penularan TB, meningkatkan kemitraan TB melalui forum koordinasi TB, peningkatan kemandirian masyarakat dalam pengendalian TB dan penguatan manajemen program. $^{9}$ Peningkatan kemandirian masyarakat dalam penanggulangan TB dilakukan dalam bentuk kegiatan: 1. Peningkatan partisipasi pasien, mantan pasien, keluarga dan masyarakat. 2 . Pelibatan peran masyarakat dalam promosi, penemuan kasus dan dukungan pengobatan TB. 3 . Pemberdayaan masyarakat melalui integrasi TB di upaya kesehatan berbasis keluarga dan masyarakat. ${ }^{4}$

Upaya meningkatkan dukungan, peran serta masyarakat dan kepedulian pihak terkait, maka Dinas Kesehatan Kabupaten Agam berupaya melibatkan dan memberdayakan masyarakat dalam pengendalian penyakit TB dengan membuat program penanggulangan TB Paru berupa program Gerakan Nagari Peduli TB. Program ini merupakan upaya untuk mengoptimalkan penemuan dan pengobatan penderita Tuberkulosis Paru di Kabupaten Agam dengan kegiatan meliputi: Pelaksanaan sosialisasi Nagari Peduli TB, pembentukan kader Nagari Peduli TB, penerbitan SK Bupati Agam tentang pembentukan Nagari Peduli TB, penyusunan buku saku kader Nagari Peduli TB, penyediaan layanan SMS Center Nagari Peduli TB dan pelaksanaan launching Nagari Peduli TB. Berdasarkan SK Bupati Agam No. 522 Tahun 2017 maka ditetapkan Nagari Magek Kecamatan Kamang Magek sebagai pilot project di Kabupaten Agam dan diharapkan pada tahun 2020 
seluruh Nagari yang ada di Kabupaten Agam telah melaksanakan Gerakan Nagari Peduli TB untuk pengendalian penyakit TB. ${ }^{10}$

Penemuan penderita TB Paru secara aktif di masyarakat sangat penting untuk mencegah penularan lebih lanjut tetapi kendala di lapangan adalah jumlah tenaga kesehatan yang ada sangat terbatas serta tidak dapat ditangani melalui pendekatan kesehatan semata, namun perlu koordinasi lintas program dan lintas sektor dengan pihak terkait termasuk masyarakat. ${ }^{11}$

Program pengendalian TB adalah; melakukan penyuluhan kepada masyarakat, (2) merujuk penderita yang batuk lebih dari 2 minggu, membagi pot dahak di posyandu, (3) pengawasan minum obat TB paru, (4) memberikan kesadaran untuk berobat secara lengkap, (5) menjelaskan usaha pencegahan dan penularan penyakit TB kepada penderita dan masyarakat, serta (6) pencatatan dan pelaporan. $^{12}$

Tindakan penanggulangan TB dapat dilakukan oleh kader TB yang berperan sebagai Pengawas Minum Obat (PMO) dengan cara mengawasi pasien TB agar menelan obat secara teratur sampai selesai pengobatan, memberi dorongan kepada pasien agar mau berobat secara teratur, mengingatkan pasien untuk periksa ulang dahak pada waktu yang telah ditentukan, memberi penyuluhan pada anggota keluarga pasien TB yang mempunyai gejala-gejala mencurigakan TB untuk segera memeriksakan diri ke unit pelayanan kesehatan. ${ }^{11}$

\section{METODE}

Penelitian ini mengunakan rancangan kualitatif deskriptif dengan teknik pengumpulan data dilakukan dengan cara wawancara mendalam, observasi dan telaah dokumen. Informan dalam penelitian ini adalah Kepala Dinas Kesehatan Kabupaten Agam, Kasie P2P Dinas Kesehatan Kabupaten Agam, Kepala Puskesmas Magek, Pemegang Program Tuberkulosis Puskesmas Magek dan Wali Nagari Magek.

Alat yang digunakan yang digunakan dalam penelitian ini adalah pedoman wawancara, lembar observasi, telaah dokumen, tape recorder dan kamera
HASIL

\section{Komponen Input}

a. Kebijakan

Berdasarkan telaah dokumen diketahui bahwa adanya SK dari Bupati Agam dan SK dari Kepala Dinas Kesehatan.

Tabel 1. Matrik triangulasi metode tentang kebijakan gerakan nagari peduli TB

\begin{tabular}{llll}
\hline Topik & Wawancara & Dokumen & $\begin{array}{l}\text { Analisis } \\
\text { Triangulasi }\end{array}$ \\
\hline Kebija & Untuk & Ada & Sangat \\
kan & meningkatkan & dokumen SK & mendukung \\
& penemuan & Bupati Agam & adanya \\
& kasus TB di & dan SK & kebijakan \\
& lapangan & Kepala & Gerakan \\
& & Dinas & Nagari \\
& & Kesehatan & Peduli TB \\
& & tentang & karena \\
& & Nagari & sangat \\
& Magek & penting \\
& sebagai pilot & untuk \\
& & project & masyara \\
& pembentu & kat \\
& kan Nagari & \\
& Peduli TB & \\
& &
\end{tabular}

\section{b. Tenaga}

Hasil telaah dokumen, observasi, wawancara mendalam didapatkan hasil bahwa adanya ketersediaan tenaga untuk pelaksanaan kebijakan Gerakan Nagari Peduli TB. Dinas Kesehatan telah membuat SK Pendamping yang bertugas untuk persiapan pembentukan Kader Nagari Peduli TB di Kabupaten Agam dan Wali Nagari juga telah membuat SK Kelompok Kader Nagari Peduli TB yang terdiri dari unsur masyarakat yang ada di Kenagarian Magek.

c. Dana

Pendanaan menjadi faktor pendukung dalam pelaksanaan suatu kegiatan suatu kebijakan.. Untuk pelaksanaan kebijakan Nagari Peduli TB tidak ada anggaran khusus untuk menunjang kegiatan Kelompok Kader Nagari Peduli TB. pendanaan hanya disediakan untuk perjalanan petugas kesehatan dari Bantuan Opersaional Kesehatan (BOK). 


\section{d. Sarana prasarana}

Hasil wawancara mendalam diketahui bahwa Dinas Kesehatan menyediakan sarana prasarana untuk menunjang kebijakan Gerakan Nagari Peduli TB dalam bentuk penyediaan sarana komunikasi berupa satu buah handphone, memberikan satu baju kaos pada masing-masing kader Nagari Peduli TB. Puskesmas Magek menyediakan media promosi dalam bentuk stiker, leaflet, spanduk, poster. Wali Nagari Magek menyediakan aula kantor Wali Nagari yang bisa digunakan oleh Kelompok Kader Nagari TB untuk melakukan kegiatan pertemuan bulanan.

\section{e. Metode}

Dari wawancara mendalam diketahui bahwa Dinas Kesehatan telah dilakukan sosialisasi terhadap masyarakat Nagari Magek dan memberikan pelatihan untuk Kelompok Kader Nagari Peduli TB. Telaah dokumen juga ditemukan daftar hadir,materi pelatihan, buku saku kader Nagari Peduli TB.

\section{Komponen Proses}

a. Perencanaan

Wawancara mendalam didapatkan hasill bahwa perencanaan kegiatan Kader Nagari TB dibuat oleh Puskesmas Magek tetapi berdasarkan telaah dokumen tidak ditemukan perencanaan kegiatan yang ada pada Kelompok Kader Nagari Peduli untuk melaksanakan kebijakan Gerakan Nagari Peduli TB.

\section{b. Pelaksanaan}

Pelaksanaan kegiatan Kelompok Kader Nagarii Peduli TB belum optimal.

Tabel 2. Matrik triangulasi metode tentang pelaksanaan gerakan nagari peduli TB

\begin{tabular}{llll}
\hline Topik & Wawancara & Dokumen & $\begin{array}{c}\text { Analisis } \\
\text { Triangulasi }\end{array}$ \\
\hline Pelak & Belum ada & Tidak & Pelaksanaan \\
sanaan & kegiatan yang & adanya & Kelompok \\
& dilakukan oleh & Standar & Kader Nagari \\
& Kader & Operasional & Peduli TB \\
& & Prosedur & berjalan biasa \\
& & kelompok & saja, laporan \\
& & Kader dalam & khusus tidak \\
& & melaksanak & ada \\
& & an kegiatan & \\
\hline
\end{tabular}

\section{c. Pengawasan}

Berdasarkan wawancara mendalam dan telaah dokumen diketahui bahwa pengawasan terhadap Kelompok Kader Nagari Peduli TB belum berjalan secara optimal.

Tabel 3. Matrik triangulasi metode tentang pelaksanaan gerakan nagari peduli TB

\begin{tabular}{llll}
\hline Topik & Wawancara & Dokumen & $\begin{array}{c}\text { Analisis } \\
\text { Triangulasi }\end{array}$ \\
\hline Penga- & Pengawasan & Tidak & Dinas \\
wasan & yang & adanya & Kesehatan \\
& dilakukan oleh & dokumen & dan \\
& Puskesmas & pengawasan & Puskesmas \\
& tidak berjalan & dan & belum \\
& secara rutin & pembinaan & optimal \\
& setiap bulan & dari & melakukan \\
& & Puskesmas & pengawasa \\
& & dan & n Kelompok \\
& & Kelompok & Kader \\
& & Kder Nagari & Nagari \\
& & Peduli TB & Peduli TB \\
\hline
\end{tabular}

\section{Komponen Output}

Hasil yang diharapkan dari kebijakan Gerakan Peduli TB berupa pelaksanaan kegiatan oleh Kelompok Kader Nagari Peduli TB belum sesuai dengan yang diharapkan.

\section{PEMBAHASAN}

\section{Komponen Input}

a. Kebijakan

Pemerintah Kabupaten Agam telah membuat kebijakan dalam bentuk Surat Keputusan Bupati No. 522 Tahun 2017 tentang penetapan Nagari Magek Kecamatan Kamang Magek sebagai pilot project di Kabupaten Agam dan telah disosialisaikan kepada Organisasi Perangkat Daerah (OPD) terkait dan masyarakat Kecamatan Kamang Magek. ${ }^{10}$

\section{b. Tenaga}

Tenaga adalah sumber daya manusia menjadii bagian yang sangat penting untuk melaksanakan suatu kebijakan kesehatan, begitu juga dengan pelaksanaan Gerakan Nagari Peduli TB di Kenagarian Magek yang harus didukung oleh tenaga yang mencukupi secara kuantitas dan kualitas. 
Terbitnya SK Bupati Agam Dinas Kesehatan membuat Surat Keputusan dari Kepala Dinas Kesehatan No. 169/SK/Dinkes/IX/2017 tentang Tim pendamping terdiri dari Kepala Bidang Pengendalian Pencegahan Penyakit, Kepala Seksi Pencegahan Penyakit Menular, dan empat orang staf Dinas Kesehatan. $^{13}$

Tim Pendamping Pembentukan Nagari Peduli TB di Kabupaten Agam dengan tujuan akselerasi pencapaian program pengendalian penyakit Tuberkulosis, bertugas mempersiapkan segala kegiatan pembentukan Nagari Peduli TB di Kabupaten Agam, menyusun buku Pedoman Kader Nagari Pedulii TB. Tim ini telah melaksanakan tugas dengan membentuk Kelompok Nagari Peduli TB di Kenagarian Magek.

Tim Pendamping melakukan advokasi terhadap Wali Nagari agar membentuk Kelompok Nagari Peduli TB yang berasal dari unsur masyarakat dan menerbitkan Surat Keputusan Wali Nagari untuk membentuk Kelompok Kader Nagari Peduli TB.

c. Dana

Pendanaan menjadi faktor pendukung dalam pelaksanaan kegiatan suatu program terutama dalam program penanggulangan TB paru. Ketersediaan dana yang cukup akan menunjang proses pelaksanaan kebijakan/program agar efektif dan efisien, sehingga suatu kebijakan/program akan menjadi terhambat apabila dana yang dibutuhkan tidak tersedia.

Dana untuk mendukung pelaksanaan kegiatan kelompok Nagari Peduli TB dalam bentuk penghargaan (dana insentif dan dana tranportasi kader) sejak terbentuknya kelompok gerakan Nagari Peduli TB dalam menjalankan kegiatan tidak tersedia alokasi dana untuk pelaksanaan kebijakan tersebut pada Puskesmas Magek maupun Kenagarian Magek.

\section{d. Sarana prasarana}

Menurut Azwar (2010) fasilitas sarana dan prasarana merupakan salah satu aspek penting dalam kelancaran organisasi. Dalam upaya menjaga kenyamanan perlu adanya sarana dan prasarana yang mendukung sehingga dapat memberikan kepuasan kepada masyarakat. ${ }^{14}$
Penyampaian informasi kepada kelompok sasaran membutuhkan sarana dan prasarana berupa media promosi. Hasil penelitian diketahui bahwa media promosi untuk menyebarluaskan informasi kebijakan Gerakan Nagari Peduli TB sudah disediakan oleh Puskesmas namun dalam jumlah terbatas. Sarana prasarana lain yang tersedia untuk pelaksanaan kebijakan gerakan nagari peduli TB berupa satu baju kaos untuk masing-masing kader, satu handphone untuk sms center dan kertas print nomor handphone sms center di kantor Wali Nagari.

\section{e. Metode}

Kebijakan tentang Gerakan Nagari Peduli TB yang telah ditetapkan berdasarkan Surat Keputusan Bupati Agam, pada perencanaan tahap pertama Dinas Kesehatan selaku Organisasi Perangkat Daerah (OPD) yang bertanggungjawab terhadap pelaksanaan kebijakan ini membuat Tim Pendamping. Pada tahapan selanjutnya tim pendamping melakukan sosialisasi, memberikan pelatihan untuk kelompok kader Nagari Peduli TB.

Sosialisasi kebijakan gerakan Nagari Peduli TB sudah dilaksanakan yang dihadiri oleh masyarakat tokoh masyarakat, tokoh adat, tokoh agama, unsur pemuda dan instansi terkait yang berada di Kecamatan Kamang Magek. Dengan sosialisasi yang dilakukan oleh Dinas Kesehatan Kabupaten Agam diharapkan bisa meningkatkan pengetahuan masyarakat Kecamatan Kamang Magek khususnya Kenagarian Magek tentang penyakit TB dan penanggulangannya TB.

Tim Pendamping memberikan pelatihan terhadap Kelompok Kader Nagari Peduli TB. Setelah mengikutii pelatihan diberikan sertifikat kepada kader Nagari Peduli TB. Pelatihan pada hakikatnya berorientasi atau memberikan penekanan pada tugas yang harus dilaksanakan oleh seorang karyawan, selain itu pelatihan juga menekankan kepada kemampuan, pengetahuan, keterampilan dan sikap karyawan. Menurut Notoatmodjo (2012); pelatihan merupakan upaya yang berkaitan dengan peningkatan kemampuan atau keterampilan karyawan yang sudah menduduki pekerjaan atau tugas tertentu. ${ }^{15}$ 
Pemberian pelatihan menggunakan media infokus dengan metode ceramah dua arah dan pemberian materi hand out dan buku saku pedoman kepada kader. Pelatihan ditujukan untuk meningkatkan kemampuan kader dalam melakukan tugas sebagai kelompok kader Nagari Peduli TB.

\section{Komponen Input}

a. Perencanaan

Menurut buku pedoman program P2TB Paru, perencanaan merupakan kegiatan pokok manajemen yang digunakan untuk memastikan sumber daya yang tersedia sekarang dan yang akan datang dialokasikan dengan efektif dan efisien untuk mencapai tujuan. Tanpa perencanaan yang matang suatu program dan kebijakan tidak akan berjalan dengan baik (Depkes RI, 2008). ${ }^{16}$

Hasil penelitian dilihat bahwa Puskesmas Magek sebagai penanggung jawab kurang melibatkan kelompok kader nagari peduli TB dalam membuat perencanaan kegiatan. Petugas Puskesmas Magek menegaskan saja agar kader bisa mengirimkan satu suspek setiap bulannya. Seharusnya Kelompok kader Nagari Peduli TB dilibatkan lebih banyak dalam membuat perencanaan sehingga kader bisa menyumbangkan tenaga dan ide.

\section{b. Pelaksanaan}

Pelaksanaan kebijakan tentang Gerakan Nagari Peduli TB belum berjalan optimal, hal ini bisa dilihat dari rendahnya kegiatan pelaksanaan oleh Kelompok Kader Nagari Peduli TB berupa penyuluhan tentang penyakit Tuberkulosis, menentukan suspek, menganjurkan penderita suspek agar memeriksakan ke Puskesmas, melakukan pencatatan dan data penderita Tuberkulosis, melakukan kunjungan rumah, membantu dan Pengawas Minum Obat (PMO).

\section{c. Pengawasan}

Hasil penelitian diketahui bahwa pengawasan dan pembinaan yang dilakukan oleh Dinas Kesehatan Agam tidak dilakukan secara khusus terhadap Kelompok Kader Nagari Peduli TB tetapi hanya dilakukan pembinaan ke Puskesmas Magek dan hanya memantau pelaksanaan program melalui laporan bulanan Puskesmas sedangkan pembinaan dan pengawasan yang dilakukan Puskesmas Magek yang seharusnya dilakukan setiap bulan bergilir ke masing-masing jorong tidak berjalan optimal.

\section{Komponen Output}

Output yang diharapkan dari penerapan kebijakan nagari peduli TB di Kanagarian Magek Kecamatan Kamang Magek Kabupaten Agam ini adalah adanya peningkatan cakupan penemuan kasus TB, khususnya di Nagari Magek yang merupakan wilayah kerja Puskesmas Magek. Berdasarkan hasil penelitian diketahui bahwa, penemuan kasus TB belum optimal, sejak dicanangkan tahun 2017 hingga dengan akhir tahun 2018 baru 5 suspek TB yang dikirim atau dilaporkan oleh kader kepada petugas Puskesmas.

Belum optimalnya implementasi kebijakan Nagari Peduli TB di Kanagarian Magek Kecamatan Kamang Magek Kabupaten Agam, menurut penulis dipengaruhi oleh beberapa faktor, dari faktor input antara lain: 1). Belum optimalnya upaya penyebarluasan informasi kepada masyarakat tentang adanya kebijakan nagari peduli TB di Kanagarian Magek, 2). Belum optimal pemanfaatan sumber daya manusia yang ada, dalam hal ini kader TB yang dari segi kuantitas sudah sangat memadai yaitu 2 orang per masing-masing jorong yang ada di Kenagarian Magek, serta dari segi kualitas juga sudah baik.

\section{SIMPULAN}

Kebijakan tentang Gerakan Nagari Peduli TB sangat mendukung untuk penanggulangan penyakit Tuberkulosis di Kabupaten Agam khususnya di Kenagarian Magek. Tenaga pelaksana Gerakan Nagari Peduli TB adalah Kelompok Kader Nagari Peduli Tuberkulosis yang dibentuk oleh tim pendamping dan Wali Nagari. Tidak ada pendanaan khusus untuk pelaksanaannya, begitu juga dengan sarana prasarana khusus untuk pelaksanaan kebijakan tentang Gerakan Nagari Peduli TB yang tidak tersedia. Kebijakan tentang Gerakan Nagari Peduli TB telah disosialisaikan kepada masyarakat Nagari Magek dan telah diberikan pelatihan kepada Kelompok Kader Nagari Peduli TB.

Proses perencanaan hanya ditentukan oleh Puskesmas Magek dan kurang melibatkan Kelompok 
Kader Nagari dalam membuat rencana kegiatan kerja. Standar Operasional Prosedur tidak tersedia sehingga pelaksanaan kegiatan Kelompok Kader Nagari Peduli belum berjalan maksimal. Pengawasan dan pembinaan terhadap Kelompok Kader Nagari Peduli TB belum berjalan dengan baik, karena pengawasan dan pembinaan dilakukan tidak rutin setiap bulannya. Output dari kebijakan tentang Gerakan Nagari Peduli tidak maksimal karena Kelompok Kader Nagari Peduli tidak melakukan kegiatan secara maksimal.

\section{SARAN}

Saran untuk Dinas Kesehatan dan Puskesmas untuk menyediakan sarana prasarana dan alokasi dana khusus untuk mendukung kegiatan Kelompok Kader Nagari Peduli TB.

Proses perencanaan kegiatan dilakukan dengan melibatkan kelompok kader. Dinas Kesehatan Agam diharapkan mampu meningkatkan pengawasan dan pembinaan terhadap Kelompok Kader Nagari Peduli TB secara rutin.

\section{UCAPAN TERIMA KASIH}

Terima kasih peneliti kepada seluruh pihak yang turut membantu dalam menyelesaikan penelitian ini.

\section{DAFTAR PUSTAKA}

1. Kementerian Kesehatan Rl. Undang - undang Kesehatan no. 36 tahun 2009 tentang kesehatan. Jakarta. Kementerian Kesehatan RI; 2009.

2. Kementerian Kesehatan. Rencana strategis kementerian kesehatan. Jakarta. Kementerian Kesehatan;2015

3. World Health Organization (WHO). Global tuberculosis report. Geneva: WHO; 2007.hlm.57

4. Kementerian Kesehatan RI. Peraturan menteri kesehatan $\mathrm{Rl}$ tentang penanggulangan tuberculosis. Jakarta: Kementerian Kesehatan $\mathrm{RI} ; 2016$.

5. Kementerian Kesehatan RI. Profil kesehatan Indonesia 2016. Jakarta: Kementerian Kesehatan $\mathrm{RI} ; 2016$.

6. Kementerian Kesehatan RI. Riset kesehatan dasar 2013. Jakarta: Kementerian Kesehatan RI; 2013.

7. Dinas Kesehatan Provinsi Sumatera Barat. Profil kesehatan provinsi Sumatera Barat. Padang: Dinas Kesehatan Provinsi Sumatera Barat; 2017.

8. Dinas Kesehatan Kabupaten Agam. Buku saku kader nagari peduli TB. Lubuk Basung: Dinas Kesehatan Kabupaten Agam; 2017.

9. Kementerian Kesehatan RI. Tuberkulosis: temukan obati sampai sembuh. Jakarta: Kementerian Kesehatan RI; 2015.

10. Pemerintah Kabupaten Agam. Surat keputusan bupati agam no. 522 tahun 2017 tentang penetapan Nagari Magek Kecamatan Kamang Magek sebagai pilot project. Lubuk Basung: Pemerintah Kabupaten Agam; 2017.

11. Kementerian Kesehatan RI. Pedoman nasional penanggulangan tuberculosis. Jakarta: Kementerian Kesehatan Rl; 2002.

12. Awofeso N, Schelokova I, Dalhatu A. Training of front line health workers for tuberculosis control: lessons from Nigeria and Kyrgiztan. Human Resources for Health. 2008;6(20):1478-91.

13. Pemerintah Kabupaten Agam. Surat keputusan kepala dinas kesehatan kabupaten Agam No. 169/SK/Dinkes/IX/2017 tentang tim pendamping. Lubuk Basung: Dinas Kesehatan Kabupaten Agam; 2017.

14. Azwar A. Pengantar administrasi kesehatan. Tangerang: Binarupa Aksara;2010.hlm.25-7.

15. Notoatmodjo. Promosi kesehatan dan perilaku kesehatan. Jakarta: PT Rineka Cipta; 2012.hlm. 51-3.

16. Kementerian Kesehatan RI. Pedoman penanggulangan tuberkulosis. Jakarta: Kementerian Kesehatan RI; 2008. 